\title{
Stability and clinical effectiveness of emulsion containing Asparagus racemosus root extract
}

\author{
Tammanoon Rungsang ${ }^{\mathrm{a}}$, Punpimol Tuntijarukorn ${ }^{\mathrm{b}}$, Kornkanok Ingkaninan ${ }^{\mathrm{c}}$, Jarupa Viyoch ${ }^{\mathrm{a}, *}$ \\ ${ }^{a}$ Department of Pharmaceutical Technology, Faculty of Pharmaceutical Sciences and \\ Centre of Excellence for Innovation in Chemistry, Naresuan University, Phitsanulok 65000 Thailand \\ b Cosmetics and Natural Products Research Centre, Faculty of Pharmaceutical Sciences and \\ Centre of Excellence for Innovation in Chemistry, Naresuan University, Phitsanulok 65000 Thailand \\ ${ }^{c}$ Department of Pharmaceutical Chemistry and Pharmacognosy, Faculty of Pharmaceutical Sciences and \\ Centre of Excellence for Innovation in Chemistry, Naresuan University, Phitsanulok 65000 Thailand
}

*Corresponding author, e-mail: jarupav@nu.ac.th

Received 10 Jun 2014

Accepted 24 Aug 2015

\begin{abstract}
Asparagus racemosus root extract was entrapped in hydroxypropyl- $\beta$-cyclodextrin (HP $\beta C D)$ by a physical mixing method and then incorporated in an oil in water $(\mathrm{o} / \mathrm{w})$ emulsion to evaluate its stability and clinical effectiveness. After the emulsion containing the HP $\beta C D$-entrapped extract was kept at $45.0 \pm 2.0^{\circ} \mathrm{C}$ for 90 days, $90 \%$ of saponins, major compounds of the extract, remained. Without entrapment with HP $\beta C D$, the amount of saponins would have decreased to $10 \%$ after storage for 60 days. After application of the emulsion containing the entrapped extract or the unentrapped extract to the outermost layer of full thickness skin, about $38 \%$ of saponins could penetrate into the skin. A higher amount of saponins was accumulated in the outermost layer applied with emulsion containing the entrapped extract. For a clinical study, measurement of the surface evaluation of wrinkles (SEw) at the zygomatic area of the face was measured at weeks 8 and 12. The average SEw value of group of subjects that applied the extract-free emulsion was significantly higher than that of the group that applied the emulsion containing the entrapped extract $(p<0.05)$. Our study indicates that in o/w emulsion, saponins in A. racemosus root extract could maintain their stability after entrapping the extract within HP $\beta$ CD. Moreover, the effectiveness of the entrapped extract on prevention of wrinkle progression was seen.
\end{abstract}

KEYWORDS: HP $\beta C D$-entrapped extract, wrinkle prevention

\section{INTRODUCTION}

Wrinkle formation accelerates from repeated exposure to UV, which results in the accumulation of free radicals and damaged molecules ${ }^{1-3}$. The UV exposure also generates inflammatory mediators and induces overexpression of enzymes involving in the degradation of collagen and elastin ${ }^{2,4,5}$. Matrix metalloproteinases (MMPs) such as MMP-1 produced by dermal fibroblasts are a group of enzymes involved in wrinkle formation ${ }^{6-8}$. Thus to prevent the progressive formation of wrinkles, it has been suggested to avoid UV exposure and to apply substances with the ability to decrease overexpression of such enzymes ${ }^{4,5,9}$.

A root part of Asparagus racemosus has been long used for ageing prevention, longevity enhancement, fertility promotion, and menopausal symptom reduction ${ }^{10,11}$. The major active constituents of $A$. racemosus root are shatavarins $\mathrm{I}-\mathrm{V}$, which are steroidal saponins ${ }^{10,12,13}$. Flavonoid compounds, including kaempferol ${ }^{13}$ and isoflavone ${ }^{14}$, and an antioxidant compound, namely racemofuran, has also been found ${ }^{15}$. The extracts from $A$. racemosus root have anti-oxidation ${ }^{16-18}$, anti-tyrosinase ${ }^{11,19}$, anti-inflammation ${ }^{20}$ and anti-ageing ${ }^{10,21}$ properties. Moreover, pretreatment of dermal fibroblasts with an extract of $A$. racemosus roots (containing $40 \%$ saponins) inhibits the overexpression of MMP-1 and restores the expression of type- 1 procollagen in UVA-irradiated fibroblasts ${ }^{22}$. These findings suggest a potential of $A$. racemosus root extract for application as an active ingredient in cosmetics to prevent future wrinkles.

To formulate a cosmetic product that is stable, effective, safe, and attractive, consideration of the physical and chemical characteristics of the interested formulation and active is required. Oil in water $(\mathrm{o} / \mathrm{w})$ emulsion is a commonly used formulation in cosmetics as it is more comfortable and less 
greasy. The incorporation of an active ingredient in the external water phase after emulsion formation is simple and potentially suitable for heat-labile active. The incorporated active ingredient can provide a rapid penetration since it is already soluble and in contact with the skin ${ }^{23,24}$. Moreover, high water content in the o/w emulsion formulation would enhance skin hydration, promoting the penetration of the active ingredient to the site of action. However, many compounds have a limiter water solubility. In addition, some compounds are unstable in aqueous soluble form.

Hydroxypropyl- $\beta$-cyclodextrin (HP $\beta C D$ ) is a partially substituted poly (hydroxypropyl) ether of cyclodextrin. This cyclodextrin derivative can improve the aqueous solubility and stability of the compound entrapped in its molecular cavity ${ }^{25}$. Additionally, cyclodextrin can interact with lipophilic components of the outer layer of skin that facilitates skin penetration ${ }^{26,27}$. In the present study, o/w emulsion containing the extract of $A$. racemosus root was prepared. The extract was entrapped in $\mathrm{HP} \beta \mathrm{CD}$, and then incorporated into the emulsion. This entrapment aimed to promote solubility, stability, skin penetration ability and biological activity of poorly water-soluble extract. To prove our idea, the chemical stability and skin penetration ability of the entrapped extract were determined by measuring amount of saponins, major compounds of the extract. Moreover, the efficacy of the emulsion containing the HP $\beta C D$-entrapped extract in preventing or slowing the progression of facial wrinkle was clinically observed.

\section{MATERIALS AND METHODS}

\section{Materials}

Shatavarin IV was purchased from ChromaDex Inc., California, USA. Human serum albumin (HSA) was a product of Sigma-Aldrich Chemie GmbH. 2,2'Azino-bis(3-ethylbenzothiazoline-6-sulphonic acid) (ABTS) was purchased from Wako, Osaka, Japan. Monoclonal antibody to shatavarin IV was supplied by Dr Kornkanok Ingkaninan, Faculty of Pharmaceutical Sciences, Naresuan University, Thailand. Peroxidase conjugated goat IgG fraction to mouse IgG Fc was purchased from MP Biomedicals, Illkirch-Graffenstaden, France. Hydroxypropyl- $\beta$ cyclodextrin (HP $\beta C D$, A.R. grade) was purchased from Sigma-Aldrich Co. Acetonitrile and methanol were analytical grade and were purchased from Merck KG.

All materials used for emulsion preparation were cosmetics grade. Glyceryl stearate and PEG100 stearate (Arlacel 165) were distributed by Croda Thailand, Bangkok, Thailand. Carbomer 934, ceteareth-6, stearyl alcohol (Cremophor A6) and ceteareth-25 (Cremophor A25) were purchased from BASF, Ludwigshafen, Germany. PEG-7 glycerol cocoate (Cetiol HE) was purchased from Cognis, Düsseldorf, Germany. Cetyl alcohol, ethylenediaminetetraacetic acid disodium salt (disodium EDTA), methyl paraben, propylene glycol and propyl paraben were distributed by Srichand United Dispensary, Bangkok, Thailand. Dimethicone was purchased from Dow Corning Corporation, Michigan, USA. Phenoxyethanol was purchased from Sigma-Aldrich, and triethanolamine (TEA) was distributed by Numsiang Trading, Bangkok.

\section{Plant material and preparation of the extract}

Fresh roots of $A$. racemosus were collected from Rayong Province, Thailand. The collected roots were chipped and dried at $50{ }^{\circ} \mathrm{C}$. Then the dried chips were ground into powder. After that $1 \mathrm{~kg}$ of the root powder was extracted with $500 \mathrm{ml}$ of acetonitrile. The resultant solution was filtered through a piece of cloth in order to remove unwanted residue and evaporated at $45^{\circ} \mathrm{C}$. Finally, the paste extract obtained was stored in airtight amber bottles at $4^{\circ} \mathrm{C}$ until used.

\section{Saponin quantification}

To control the extract quality of each batch, the amount of saponins in the extract, equivalent to shatavarin IV, was determined by using enzymelinked immunosorbent assay (ELISA) according to the method used in previous study ${ }^{28}$. Briefly, $100 \mu 1$ of $1 \mu \mathrm{g} / \mathrm{ml}$ shatavarin IV-HSA conjugate in $50 \mathrm{mM}$ carbonate buffer (pH 9.6) was added in each well of 96 wells plate (Maxisorb Nunc, Roskilde, Denmark) and incubated at $37^{\circ} \mathrm{C}$ for $1 \mathrm{~h}$. The plate was then washed three times with $0.05 \%$ Tween 20 phosphate buffered saline (TPBS). After that $300 \mu \mathrm{l}$ of $0.2 \%$ gelatin in phosphate buffered saline was added and incubated at $37^{\circ} \mathrm{C}$ for $1 \mathrm{~h}$ to reduce non-specific binding. Fifty microlitres of various concentrations of shatavarin IV or the extract in $20 \%$ methanol and $50 \mu \mathrm{l}$ of the monoclonal antibody solution were added and incubated at $37^{\circ} \mathrm{C}$ for $1 \mathrm{~h}$. The plate was washed three times with TPBS. After washing, $100 \mu \mathrm{l}$ of 1:1000 diluted solution of peroxidase conjugated goat IgG fraction to mouse IgG Fc was added and kept at $37^{\circ} \mathrm{C}$ for $1 \mathrm{~h}$. After incubation, the plate was washed three times with TPBS and then $100 \mu \mathrm{l}$ of a substrate solution 
consisting of $0.3 \mathrm{mg} / \mathrm{ml}$ of ABTS in $100 \mathrm{mM}$ citrate buffer ( $\mathrm{pH} 4.0$ ) containing $0.003 \% \mathrm{H}_{2} \mathrm{O}_{2}$ was added and incubated at $37^{\circ} \mathrm{C}$ for $15 \mathrm{~min}$. The optical density of the resultant solution was measured by using a microplate reader (Model CeresUV900, BioTek instrument, Vermont, USA) at $405 \mathrm{~nm}$. The study was performed in triplicate.

\section{Entrapment of the extract within $\mathrm{HP} \beta C D$}

The extract and $\mathrm{HP} \beta C D$ at various ratios (extract:HP $\beta C D, 1: 0-1: 5$ ) were accurately weighed. The homogeneous powder of the HP $\beta C D$-entrapped extract was obtained by mixing method using a mortar and pestle. Briefly, $1 \mathrm{~g}$ of $\mathrm{HP} \beta \mathrm{CD}$ powder was added in the glass mortar, and the desired quantity of the paste extract was then added and gently kneaded for $1 \mathrm{~h}$ to get the homogeneously moist powder of the samples. The moist samples were kept in a dessicator until they were dried, and the dried samples were screened through an 80 mesh sieve corresponding to a maximum particle size of about $0.18 \mathrm{~mm}$. The entrapped extracts were kept in airtight amber bottles at $4^{\circ} \mathrm{C}$ until used.

\section{HPßCD-entrapped extract solubility}

The solubility of the entrapped extract compared with the unentrapped extract was determined by measuring amount of major compounds, saponins dissolved in an aqueous vehicle. The desired quantity of the test samples, equivalent to $100 \mathrm{mg}$ extract, was added to $10 \mathrm{ml}$ of distilled water. Then the resulting suspensions were shaken at room temperature for $24 \mathrm{~h}$. After equilibrium, the samples were filtered through a $0.45 \mu \mathrm{m}$ membrane filter. The concentration of saponins in the resulting solutions was then determined by ELISA technique as mentioned above. The study was performed in triplicate.

\section{DSC thermogram of the HP $\beta C D$-entrapped extract}

Differential scanning calorimeter (DSC; Model DSC7; Perkin Elmer, Norwalk, Connecticut, USA) was used to investigate thermogram pattern of the entrapped extract as compared to that of the unentrapped extract and the free HP $\beta C D$. The sample of the entrapped extract was prepared from 1-4 weight ratio of extract to HP $\beta C D$, and contained the extract with an equivalent amount of the unentrapped extract sample. The samples were dried to a constant weight in a desiccator before testing, and the solid aluminium close pan was used to fill each sample.
The temperature was set to raise from $30^{\circ} \mathrm{C}$ to $350^{\circ} \mathrm{C}$. The heat rate was $10^{\circ} \mathrm{C} / \mathrm{min}$.

\section{Preparation of emulsion containing the extract}

The water phase ingredients composing of $1 \% \mathrm{w} / \mathrm{w}$ Cremophor A25, 0.1\% w/w disodium EDTA, 2\% $\mathrm{w} / \mathrm{w}$ propylene glycol and $70 \% \mathrm{w} / \mathrm{w}$ water were heated to $75^{\circ} \mathrm{C}$ while the oil phase ingredients composing of $2 \% \mathrm{w} / \mathrm{w}$ Arlacel 165, 1\% w/w Cetiol HE, $2 \% \mathrm{w} / \mathrm{w}$ cetyl alcohol, $1 \% \mathrm{w} / \mathrm{w}$ Cremophor A6 and $3 \% \mathrm{w} / \mathrm{w}$ dimethicone were heated to $70^{\circ} \mathrm{C}$. The water phase was then added to the oil phase with stirring. After cooling down, the preservatives including $0.5 \% \mathrm{w} / \mathrm{w}$ phenoxyethanol and $0.25 \%$ $\mathrm{w} / \mathrm{w}$ paraben solution $(20 \% \mathrm{w} / \mathrm{w}$ methylparaben and $2 \% \mathrm{w} / \mathrm{w}$ propylparaben in propylene glycol) were added. The thickening agent, carbomer (carbopol 934) was added to a final concentration of $0.5 \% \mathrm{w} / \mathrm{w}$ in emulsion, and $0.2 \% \mathrm{w} / \mathrm{w}$ TEA was then added to neutralize the carbomer.

To prepare emulsion containing the extract, the entrapped extract with 1-4 weight ratio of extract to HP $\beta C D$, or the unentrapped extract was simply added in the prepared emulsion with gentle stirring. Both preparations, i.e., emulsion with the entrapped extract and with the unentrapped extract, contained equivalent amount of the extract, $0.5 \% \mathrm{w} / \mathrm{w}$ of emulsion.

\section{Determination of characteristics of the prepared emulsion}

The mean droplet size and size distribution (polydispersity, PI) were analysed by a photon correlation spectroscopy employing a Zetasizer (Model Nano ZS90, Malvern Instrument, Worcestershire, UK). This instrument was fitted with a $4 \mathrm{~mW}$ He-Ne diode laser operating at $633 \mathrm{~nm}$. Emulsions were diluted with deionized water to eliminate the effect of viscosity caused by the ingredients. Droplet size and droplet size distribution were obtained as the average of three times. The viscosity was determined by viscometer (Brookfield DV III, Phoenix, Arizona, USA) equipped with a cone and plate (plate diameter $40 \mathrm{~mm}$, cone angle $4^{\circ}$ ). The measurement was carried out at a temperature of $30^{\circ} \mathrm{C}$ with torque of $10 \mathrm{rpm}$. The $\mathrm{pH}$ was determined using a pH meter (Model delta 320, Mettler Toledo, Guangzhou, China).

\section{Stability study}

The emulsion containing the HP $\beta C D$-entrapped extract was stored in a well-closed glass container at an accelerated temperature, $45.0 \pm 2.0^{\circ} \mathrm{C}$ for 
90 days $^{29}$. The physical characteristics including droplet size, viscosity, and $\mathrm{pH}$ at before and after stability test under storage condition were determined. The study was run in triplicate.

To determine whether the entrapment with HP $\beta C D$ could maintain the chemical stability of the extract, the saponin content in emulsion containing the entrapped extract was compared with emulsion containing the unentrapped extract. After storage at $45.0 \pm 2.0^{\circ} \mathrm{C}$ for 90 days, their saponin contents were determined periodically by ELISA as described above.

\section{In vitro permeation study}

To determine weather HP $\beta C D$ could influence the skin permeation of saponins, the permeation ability of saponins in the emulsion with and without entrapped extract were compared. The foreskin of human excess surgery was used in this study (male, 1 year of age). After washing with phosphate buffered saline ( $\mathrm{pH} 7.4)$, the washed tissues were immersed in $10 \mathrm{ml}$ of DMEM containing $20 \%$ FBS and $1 \%$ penicillin/streptomycin solution. The tissue-immersed medium was kept at $-80^{\circ} \mathrm{C}$ until used.

In vitro permeation study was determined using a Franz diffusion cell (Model no. 57-951-061, Meditron, Germany). The area of the skin tissue exposed to the receptor medium (phosphate buffered saline, $\mathrm{pH}$ 7.4) was $1.77 \mathrm{~cm}^{2}$, and the receptor chamber volume was $13 \mathrm{ml}$. The skin tissue was mounted on the receptor compartment with the epidermal side facing upward into the donor compartment. The temperature of the receptor medium was set at $37^{\circ} \mathrm{C}$, and the skin temperature was controlled at $32 \pm 1^{\circ} \mathrm{C}$ as described previously ${ }^{29,30}$. One hundred milligrams of the emulsion containing the HP $\beta C D$ entrapped extract or the unentrapped extract were evenly spread on the surface of stratum corneum (st. corneum), outermost layer of epidermis. The donor compartment was covered with a sheet of aluminium foil and wrapped with a piece of stretchable plastic film to prevent evaporation/drying. The time intervals for sampling receptor medium were 15,30 , $60,180,360$, and 540 min after study. The amount of saponins in the collected medium was determined by ELISA.

After 540 min of study, the skins were removed from the Franz diffusion cell and washed with sterile water to remove the excess emulsion. The st. corneum layer exposed with emulsion was removed by stripping the skin tissue 10 times with adhesive tapes $^{30-32}$. The adhesive tapes or the tape-stripped skin (viable skin without st. corneum) were homogenized in acetonitrile and sonicated for $30 \mathrm{~min}$ in order to extract the saponin retained. After that, the samples were filtered through a $0.45 \mu \mathrm{m}$ membrane filter, and the amount of saponins was determined by ELISA. The study was run in triplicate.

\section{Clinical study on effectiveness of the emulsion containing the extract on preventing progressive wrinkles}

The study protocol (project code: 5503010004 ) was approved by Naresuan University Human Ethics Committee. The study design was a home-used study, randomized, double-blinded, placebo controlled trial. A simple randomization method was used to divide the healthy female volunteers into two groups to attend the test (20 subjects) and control (20 subjects) groups. The random code was prepared using a random table. Each code was concealed and kept by independent staff.

In this study, the effects of the emulsion containing the HP $\beta C D$-entrapped extract (the test preparation) focused on skin wrinkle, skin moisture and skin irritation and was compared to the effects of the control preparation. The control preparation was the emulsion prepared using the same ingredients as the test preparation but without the extract.

All subjects received written description of the instructions and assigned products. They were instructed on how to apply the assigned products (the test preparation for the test group and the control preparation for the control group) on their clean facial skins once a day at bed time. The duration of assigned product application was 12 weeks. All subjects were asked to avoid sun exposure and sunlamps during the study periods, and received the sunscreen product with sun protection factor (SPF) 15 which was applied to the face about $0.5 \mathrm{~g}$ once a day in the morning. The sunscreen agents in this product were $2 \% \mathrm{w} / \mathrm{w} \mathrm{TiO} 2$ and $2 \% \mathrm{w} / \mathrm{w}$ octyl methoxycinnamate. At the day of the scheduled visit, subjects did not apply any powder or cosmetic colour formulations to their faces.

All assessments were performed at the cosmetics and Natural Products Research Centre (Cosnat), Naresuan University, Phitsanulok, Thailand. The testing room was controlled temperature of $27 \pm 2{ }^{\circ} \mathrm{C}$ and $55 \% \pm 5 \%$ air humidity. All subjects had to rest for at least $30 \mathrm{~min}$ in a testing room before the assessment. The baseline values of the surface evaluation of wrinkles (SEw, Visiometer VD 300, Courage and Khazaka electronic $\mathrm{GmbH}$, Cologne, Germany), moisture content (Cor- 
neometer CM 825, Courage and Khazaka electronic $\mathrm{GmbH}$ ), pH (Skin-pH-Meter PH 900, Courage and Khazaka electronic $\mathrm{GmbH}$ ) and erythaema (redness) (Mexameter MX 18, Courage and Khazaka electronic $\mathrm{GmbH}$ ) of the zygomatic area of the face were determined before starting the application (week 0, baseline characteristics). These parameters were measured again at week $2,3,4,6$, 8 , and 12 of the study period. At each visiting time, the measurements were performed before the application of the preparations on that day. In addition, adverse effects of the preparations during the study were observed to assess the mildness of product. This assessment was determined by a dermatologist using the visual grading scale of Frosch \& Kligman and Colipa ${ }^{33}$. The scale varied from 0-4 as follows: erythaema, $0=$ no evidence of erythaema, $0.5=$ minimal or doubtful erythaema, $1=$ slight redness, spotty and diffuse, $2=$ moderate and uniform redness, $3=$ intense redness and $4=$ fiery redness; scaling, $0=$ no evidence of scaling, $0.5=$ dry without scaling or appears smooth and taut, $1=$ fine or mild scaling, $2=$ moderate scaling and $3=$ severe scaling with large flakes; and oedema, $0=$ absence of oedema and $1=$ presence of oedema.

The quality control of the study was evaluated by determining the subject compliance including weighing the given preparations and checking description of the preparation using written by each subject.

\section{Statistical analysis}

All data were expressed as the mean \pm standard deviation. Student's $t$-test was used for comparison between the averages of two independent groups. The $p$-value of less than 0.05 was considered statistically significant.

\section{RESULTS AND DISCUSSION}

\section{The appearance and saponin content of} A. racemosus root extract

The root extract of $A$. racemosus provided brown paste with the yield of $4 \% \mathrm{w} / \mathrm{w}$ of dried root. By ELISA analysis, the amount of major components, saponins was $40.2 \pm 6 \% \mathrm{w} / \mathrm{w}$ of the extract.

\section{Physical characteristics of the HP $\beta C D$-entrapped extract}

The physical mixing of the paste extract with $\mathrm{HP} \beta C D$ provided a powder of the HP $\beta C D$-entrapped extract. Table 1 shows the concentration of saponins
Table 1 Concentration of saponins detected in different entrapped extract mixtures $(n=3)$.

\begin{tabular}{cc}
\hline Extract: $\mathrm{HP} \beta \mathrm{CD}(\mathrm{g})$ & $\begin{array}{c}\text { Total amount of saponins } \\
(\mathrm{mg} / \mathrm{ml} \text { water })\end{array}$ \\
\hline $1: 0$ & $0.64 \pm 0.02$ \\
$1: 1$ & $1.28 \pm 0.06^{* *}$ \\
$1: 3$ & $1.68 \pm 0.12^{*}$ \\
$1: 4$ & $3.32 \pm 0.33^{* *}$ \\
$1: 5$ & $3.48 \pm 0.32^{* *}$ \\
\hline
\end{tabular}

Statistically significant different from the 1:0 ratio; " $p<0.05 ;{ }^{* * *} p<0.01$; measured as mean \pm SD.

detected in water after the desired quantity of the entrapped extract (extract: $\operatorname{HP} \beta C D, 1: 1$ to $1: 5$ ) containing $100 \mathrm{mg}$ of the extract and $100 \mathrm{mg}$ of the unentrapped extract (extract: $\mathrm{HP} \beta C D, 1: 0$ ) was dissolved in $10 \mathrm{ml}$ water $(n=3)$. Higher concentration of saponins detected implies higher amount of the extract dissolved. Increasing ratio of HP $\beta C D$ in the entrapped extract resulted in increasing amount of saponins detected: 5-fold higher concentration as compared to the unentrapped extract. However, a great difference in saponins concentration between the entrapped extract of 1-4 and 1-5 weight ratio (extract to HP $\beta C D$ ) was not seen. It is possible that, at 1-4 weight ratio, system is saturated with $\mathrm{HP} \beta C D$ to incorporated more extract. According to above results, the $1-4$ ratio of extract to $\mathrm{HP} \beta C D$ was the ratio selected to prepare the entrapped extract used in further studies. In $25 \mathrm{mg}$ of the HP $\beta C D$-entrapped extract contained $5 \mathrm{mg}$ extract and $2.0 \pm 0.1 \mathrm{mg}$ of saponins.

DSC was used to confirm the interaction between the extract and HP $\beta C D$ molecule. The principle of this method is when the extract is entrapped in an $\mathrm{HP} \beta C D$ cavity or interacts with $\mathrm{HP} \beta C D$, its melting point changes to a different temperature or disappears ${ }^{29}$. Fig. 1a shows that the extract exhibited blurred melting peaks at about 90 and $180^{\circ} \mathrm{C}$ while $\mathrm{HP} \beta \mathrm{CD}$ (Fig. 1b) exhibited a sharp peak at $160^{\circ} \mathrm{C}$. The appearance of new peaks at about 149 and $155^{\circ} \mathrm{C}$ and the disappearance of extract peaks were observed in the HP $\beta C D$-entrapped extract (Fig. 1c), indicating a possible interaction between extract and HP $\beta C D$ molecules during the mixing procedure.

\section{Physical characteristics and stability of the emulsion containing the extract}

The prepared emulsion containing the HP $\beta C D$ entrapped extract was white opaque with $\mathrm{pH}$ 5.6. 

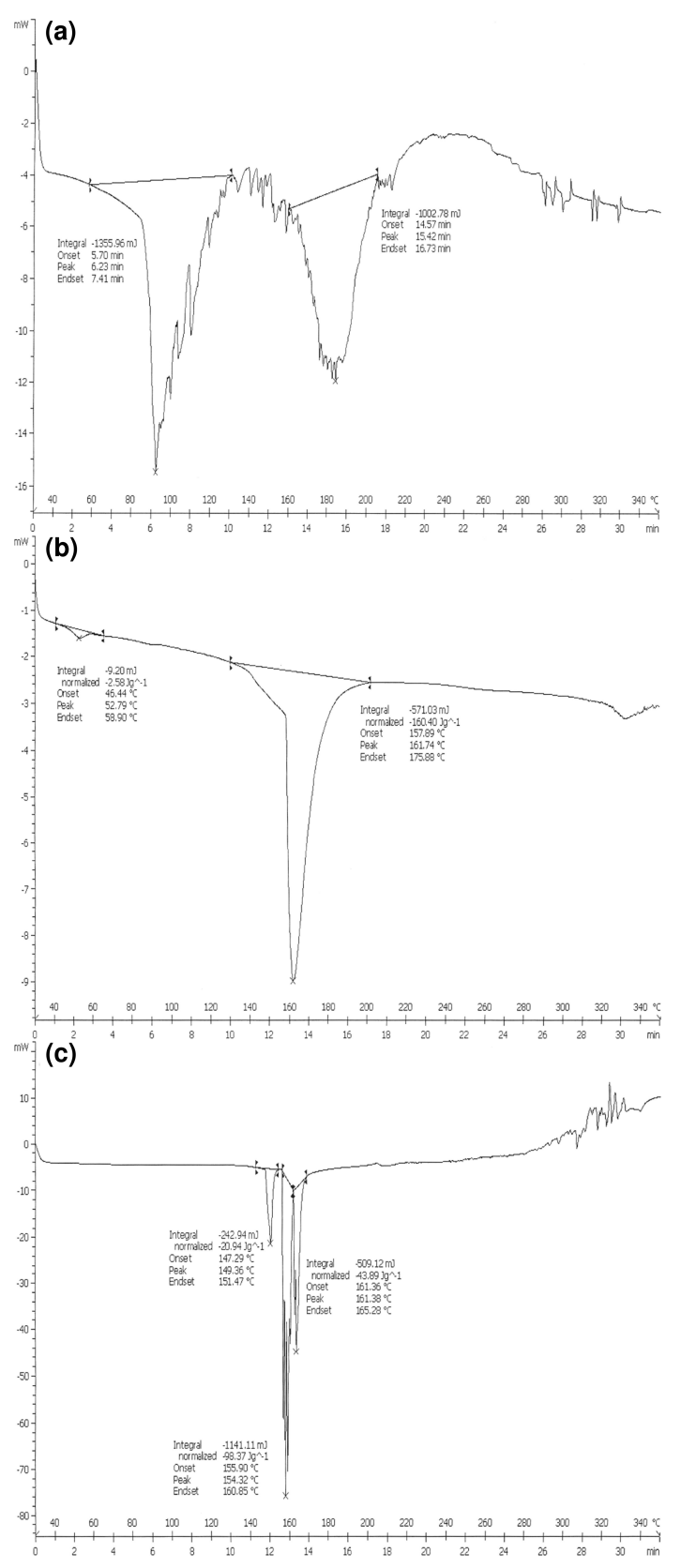

Fig. 1 (a) DSC thermograms of extract; (b) HP $\beta C D$; (c) HP $\beta C D$-entrapped extract.

The droplet size of internal phase was $318 \pm 16 \mathrm{~nm}$ with polydispersity (PI) of $0.3 \pm 0.01$. The viscosity was $1091 \pm 13 \mathrm{cP}$. Table 2 shows physical characteristics of the preparation before (fresh preparation) and after 90 days of the study. The appearance, mean droplet size, PI and viscosity were not significant difference between the freshly prepared and after stability tested emulsion. This might be due to the external phase viscosity as carbopol 934 slows
Table 2 Characteristics of the prepared emulsion containing the HP $\beta C D$-entrapped extract after storage $(n=3)$.

\begin{tabular}{lccc}
\hline Conditions & pH & $\begin{array}{c}\text { Droplet size } \\
(\mathrm{nm} / \mathrm{PI})^{\dagger}\end{array}$ & $\begin{array}{c}\text { Viscosity } \\
(\mathrm{CPs})^{\dagger}\end{array}$ \\
\hline $\begin{array}{l}\text { Fresh preparation } \\
\text { After storage }^{\dagger}\end{array}$ & $5-6$ & $319 \pm 17 / 0.3 \pm 0.01$ & $1091 \pm 13$ \\
\hline${ }^{\dagger}$ Measured as mean \pm SD. & $355 \pm 41 / 0.3 \pm 0.04$ & $1095 \pm 15$ \\
$*$ After storage for 90 days at $45.0 \pm 2.0^{\circ} \mathrm{C}$. &
\end{tabular}

Table 3 Percentage of saponins remained after the preparations were kept at an accelerated temperature $(n=3)$.

\begin{tabular}{lcc}
\hline Conditions & HP $\beta C D$-entrapped & Unentrapped \\
\hline Fresh preparation & $100.0 \pm 3.1$ & $100.0 \pm 2.8$ \\
After storage 30 d & $90.5 \pm 1.5^{\mathrm{a}}$ & $88.4 \pm 2.1^{\mathrm{a}}$ \\
After storage 60 d & $89.7 \pm 0.7^{\mathrm{a}}$ & $79.7 \pm 5.1^{\mathrm{ab}}$ \\
After storage 90 d & $89.1 \pm 2.7^{\mathrm{a}}$ & $77.8 \pm 4.0^{\mathrm{ab}}$ \\
\hline
\end{tabular}

${ }^{\dagger}$ After storage at $45.0 \pm 2.0^{\circ} \mathrm{C}$.

${ }^{a}$ statistically significant difference from the fresh preparation; $p<0.05$.

${ }^{\mathrm{b}}$ statistically significant from the emulsion with the HP $\beta C D$-entrapped extract; $p<0.05$.

the coalescence or separation of the prepared emul$\operatorname{sion}^{34}$.

The percentage of saponins in the emulsion containing the entrapped extract or the unentrapped extract after storage at accelerated conditions is shown in Table 3. The initial amount of saponins averaged $20.0 \pm 0.3 \mathrm{mg}$ in $100 \mathrm{~g}$ of emulsion containing the entrapped extract and $19.9 \pm 0.3 \mathrm{mg}$ in $100 \mathrm{~g}$ emulsion containing the unentrapped extract. A significant difference in saponins content between two preparations was observed after 60day storage. Without interaction with $\mathrm{HP} \beta C D$, the amount of saponins was lesser than $90 \%$ after storage for 60 days. The entrapment in HP $\beta C D$ cavity and/or the interaction with HP $\beta C D$ might affect the chemical properties of the extract ${ }^{25,35}$, thus preventing the chemical changes and/or degradation of saponins.

\section{The permeation of saponins through the skin}

The amount of saponins that penetrated through skin at various times is shown in Table 4. At the last collecting time (540 min of the study), a cumulative amount of saponins found in the medium of both preparations was about $13 \%$ of total amount of saponins incorporated in the preparation, while amount of saponins accumulated into the viable skin layer (epidermis and dermis) was about $25 \%$. 
Table 4 Cumulative percentage of saponins penetrated through the full thickness of skin $(n=3)$.

\begin{tabular}{lccc}
\hline Time (min) & HP $\beta C D$-entrapped & Unentrapped $^{\dagger}$ & Site $^{*}$ \\
\hline 15 & nd & nd & Rm \\
30 & nd & nd & Rm \\
60 & nd & nd & Rm \\
180 & $12.0 \pm 0.8$ & $11.9 \pm 1.4$ & Rm \\
360 & $12.5 \pm 0.5$ & $13.1 \pm 1.8$ & $\mathrm{Rm}$ \\
540 & $12.8 \pm 1.1$ & $12.7 \pm 0.9$ & $\mathrm{Rm}$ \\
540 & $10.9 \pm 0.5$ & $7.9 \pm 0.9^{* *}$ & $\mathrm{Sc}$ \\
540 & $25.8 \pm 3.9$ & $26.2 \pm 5.5$ & Ed \\
\hline
\end{tabular}

$\dagger$ Statistical significance from the emulsion with the entrapped extract; ${ }^{* *} p<0.01$; nd, not detected.

$*$ Rm, receptor medium; Sc, st. corneum; Ed, viable skin layer (epidermis and dermis).

This implies that after application to the dorner site for $540 \mathrm{~min}$, about $38 \%$ of saponins could penetrate the st. corneum, the outermost skin barrier. The rest of $62 \%$ was excess on the skin and/or degraded or interacted with skin components. As a comparison between emulsion with the HP $\beta C D$ entrapped extract and with the unentrapped extract, significantly higher amount of saponins accumulated in st. corneum applied with emulsion containing the entrapped extract. As cyclodextrin is able to interact with lipophilic components of st. corneum ${ }^{26,27}$, it might induce the formation of a saponin-HP $\beta C D$ reservoir and generate higher accumulation of saponins in the st. corneum.

For penetration through deeper skin layer, the free saponins must be released from the st. corneum before partitioning to a viable layer. Generally, the partition of a given compound depends not only on the st. corneum concentration but also on its solubility in a more hydrophilic deeper layer ${ }^{29,36}$. In the present study, there was no difference in amount of saponins accumulated in the viable layer between skin applied with emulsions with and without the entrapped extract. It is possible that the saponin solubility in the viable skin is a rate limiting step of the penetration. However, the formed saponin$\mathrm{HP} \beta C D$ reservoir in the st. corneum may constitute an advantage since the saponins could remain and exert a local activity at the site of action for a longer time.

\section{Skin tolerance and effectiveness of the emulsion containing the extract on preventing progressive wrinkles}

To control the quality, the preparations used were weighed, and the application frequency was
Table 5 Demographic and skin properties of subjects enrolled in the study.

\begin{tabular}{|c|c|c|c|}
\hline $\begin{array}{l}\text { Characteristics } \\
\text { (mean (SD)) }\end{array}$ & $\begin{array}{l}\text { Control group } \\
\quad(n=20)^{\dagger}\end{array}$ & $\begin{array}{l}\text { Test group } \\
(n=20)^{\dagger}\end{array}$ & $p^{*}$ \\
\hline Age & $43.9(7.1)$ & $41.3(6.1)$ & 0.211 \\
\hline $\mathrm{SEw}^{\mathrm{a}}$ & $28.2(1.3)$ & $28.1(1.3)$ & 0.794 \\
\hline Moisture (AU) ${ }^{\mathrm{b}}$ & $37.4(1.4)$ & 37.1 (1.5) & 0.484 \\
\hline $\mathrm{pH}$ & $5.7(0.3)$ & $5.8(0.4)$ & 0.377 \\
\hline Erythema (AU) & $316.6(5.0)$ & 313.9 (6.9) & 0.157 \\
\hline \multicolumn{4}{|c|}{$\begin{array}{l}20 \text { Thai females. } \\
2 \text {-Group student's } t \text {-test with a significance level of } \\
0.05 \text {. } \\
\text { a SEw, surface evaluation of wrinkles. } \\
\text { b AU, arbitrary unit; one unit represents a water content } \\
\text { of st. corneum of } 0.02 \mathrm{mg} / \mathrm{cm}^{2}\end{array}$} \\
\hline
\end{tabular}

checked during the study. On average, $0.6 \mathrm{~g} /$ day of the test (emulsion containing the HP $\beta C D$-entrapped extract) or control (emulsion without the extract) preparation was used by each subject. Approximately $0.12 \mathrm{~g}$ of saponins was contained in $0.6 \mathrm{~g}$ of emulsion with the entrapped extract (calculated from the average, $20.0 \pm 0.3 \mathrm{~g}$ of saponins in $100 \mathrm{~g}$ of emulsion). One hundred percent of subjects used the preparations every night and SPF 15 sunscreen every morning.

Table 5 shows the demographic and mean baseline characteristics of the subjects. The enrolled subjects ranged in age from 30-55 years. There was no significant difference in the average age between the control ( $43.9 \pm 7.1$ years) and test $(41.3 \pm 6.1$ years) groups. The baseline values of all skin properties obtained from the zygomatic area of the face of the test group did not show significant difference when compared with the control group. Subjects in both groups had no erythaema, scaling, or oedema as evaluated by a dermatologist.

The skin properties of the subjects before and after application of the test and control preparations are given in Fig. 2a-d, and examples of images from Visiometer VD 300 indicating the wrinkle depth of zygomatic areas of faces of subjects are shown in Fig. 3. Focusing on the surface evaluation of wrinkles (SEw), which reflects the depth of wrinkles (Fig. 2a), the averaged SEw value of the control group was significantly higher than that of the test group $(p<0.01)$ at weeks 8 and 12 of the study. This significant difference was from the increasing in SEw value of the control group, indicating the preventive effect of the emulsion containing the entrapped extract on wrinkle progression in the test 

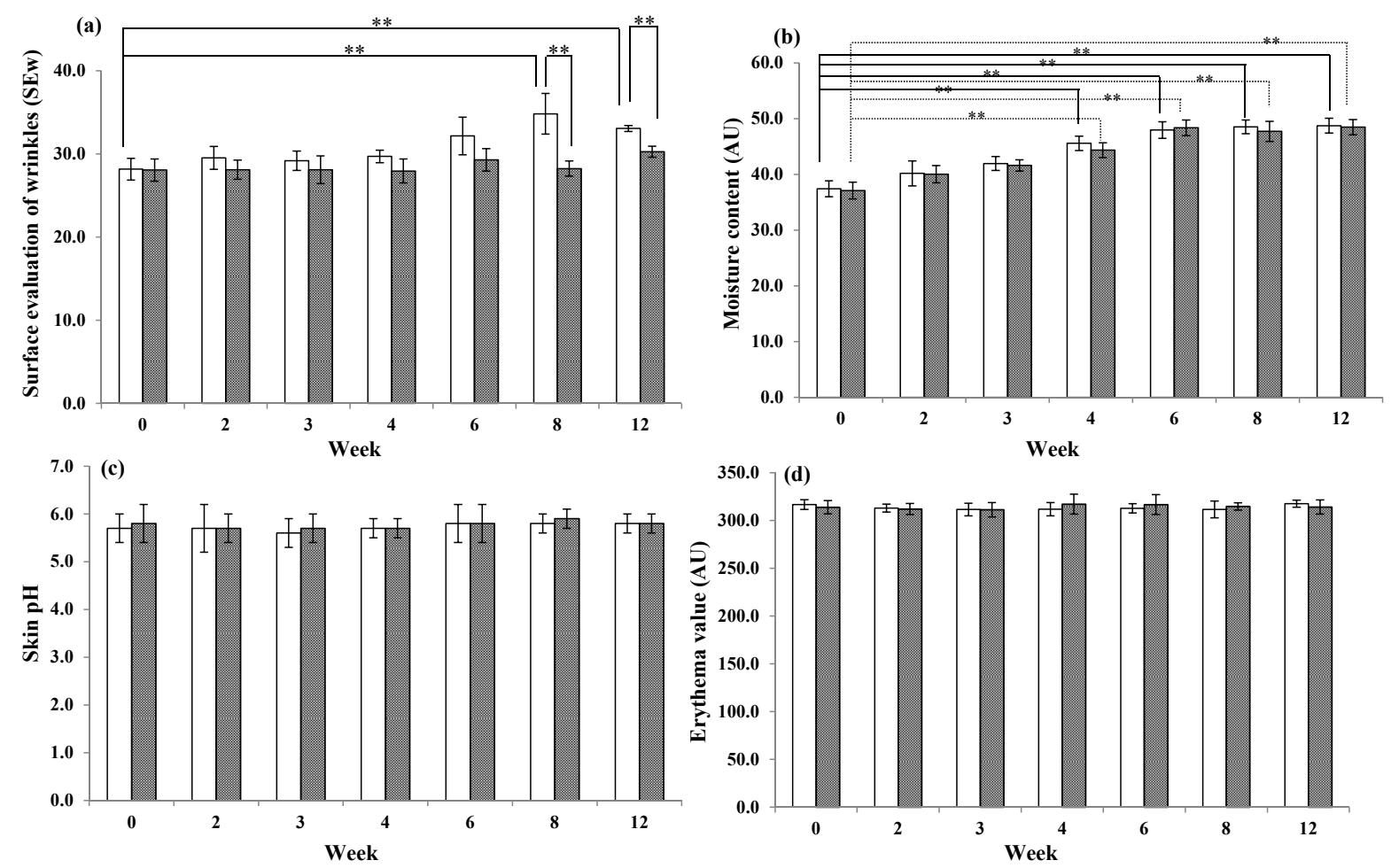

Fig. 2 (a) The averaged values of surface evaluation of wrinkles (SEw); (b) moisture content (one arbitrary unit, AU, represents water content of st. corneum of $0.02 \mathrm{mg} / \mathrm{cm}^{2}$ ); (c) skin $\mathrm{pH}$; (d) erythaema; of the facial zygomatic areas of subjects during efficacy study. Value at week 0 is the baseline value. Each bar is the mean value of 20 subjects and error bars are the SD of the mean; ${ }^{* *} p<0.01$, when compared between two groups. The white and grey bars are control and test groups, respectively.

group. The moisture content, meaning to boundwater content in the st. corneum increased from baseline value (Fig. 2b) was found in both control and test groups. The containing of moisturizing ingredients, such as propylene glycol, cetyl alcohol, stearyl alcohol, and ceteareth in the emulsion formula would enhance the skin moisture.

In the present study, the clinically preventive effect of the emulsion containing the entrapped extract indicates that the penetrated amount of the extract and/or saponins to skin is enough for showing biological effects. Such prevention might involve a combination effects in different steps of the wrinkle progression. The antioxidant compounds contained in $A$. racemosus root extract would minimize skin damages from free radical activity. The extract might also decrease the production of inflammatory mediators and MMP- $1^{22}$ which play a major role in collagen degradation. Additionally, the preventing wrinkle progression of the test preparation might be elevated by using the sunscreen product with sun protection factor of 15 throughout the course of the study ${ }^{37}$.
Safety evaluation of cosmetic products during application is essential. In this study, redness (erythaema value), skin $\mathrm{pH}$, and visual evaluations were used to assess the tolerance of the subjects to the preparations after application for 12 weeks. There were no significant difference in skin pH (Fig. 2c) or erythaema (Fig. 2d) values between the baseline and at any evaluated times. There was no erythaema, scaling, or oedema in any of the groups, according to Frosch \& Kligman. The $\mathrm{pH}$ value of preparations that mimics the skin $\mathrm{pH}$ would not disrupt the skin barrier function, resulting in mild preparation to the skin.

\section{Conclusions}

Our study indicates that by interaction with HP $\beta C D$, A. racemosus root extract could maintain its stability at an accelerated temperature after incorporating it in formulation such as o/w emulsion. Moreover, the effectiveness of the extract on prevention of wrinkle progression on zygomatic area of the face in healthy female was clinically observed. Further studies using a larger number of subjects and longer dura- 


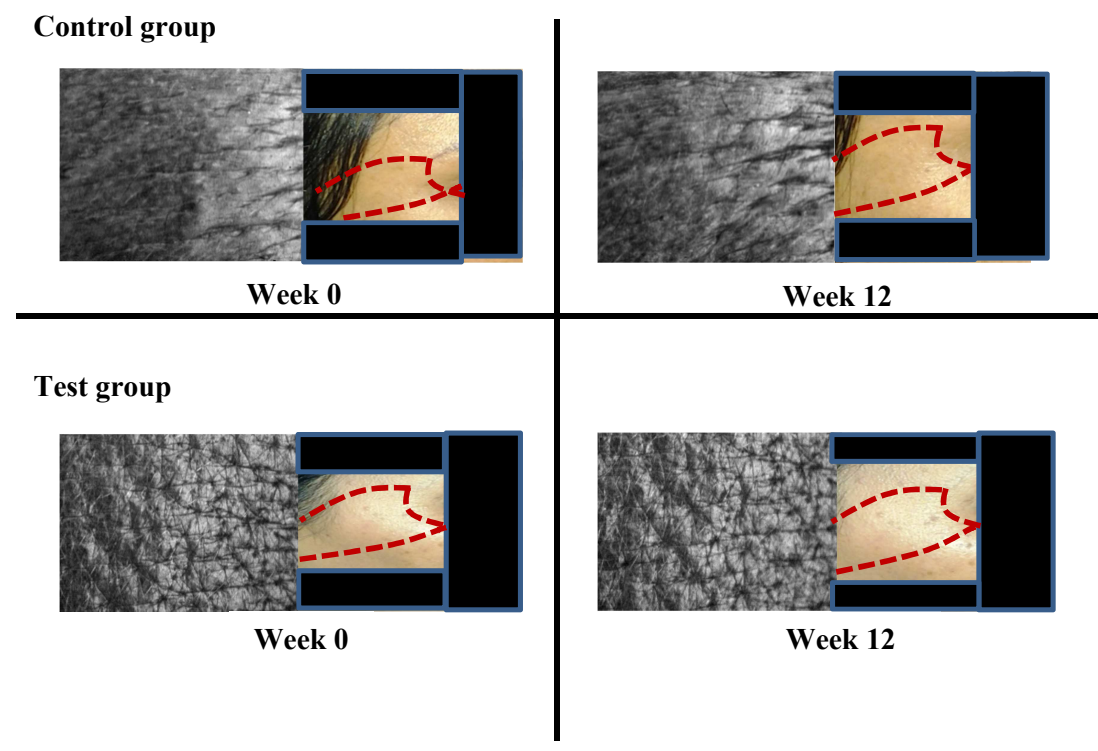

Fig. 3 Examples of photos of skin wrinkles of facial zygomatic areas (within red dashed line) taken from Visiometer VD 300 at week 0 and week 12 of the study. The control group is the group of subjects who received the control preparation (emulsion without the extract), and the test group is the group of subjects who received the test preparation (emulsion with the HP $\beta C D$-entrapped extract).

tion of product application should be performed to provide stronger evidence on the efficacy and safety of this product.

Acknowledgements: Financial support is from National Nanotechnology Centre (NANOTEC), Bangkok, Thailand, and the facility support is form Centre of Excellence for Innovation in Chemistry (PERCH-CIC), Office of the Higher Education Commission and Faculty of Pharmaceutical Sciences, Naresuan University.

\section{REFERENCES}

1. Wang F, Smith NR, Tran BAP, Kang S, Voorhees JJ, Fisher GJ (2014) Dermal damage promoted by repeated low-level UV-A1 exposure despite tanning response in human skin. JAMA Dermatol 150, 401-6.

2. Amano S (2009) Possible involvement of basement membrane damage in skin photoaging. $J$ Investig Dermatol Symp Proc 14, 2-7.

3. Pillai S, Oresajo C, Hayward J (2005) Ultraviolet radiation and skin aging: roles of reactive oxygen species, inflammation and protease activation, and strategies for prevention of inflammation-induced matrix degradation-a review. Int J Cosmet Sci 27, 17-34.

4. Kim J, Lee CW, Kim EK, Lee SJ, Park NH, Kim HS, Kim HK, Char K, et al (2011) Inhibition effect of Gynura procumbens extract on UV-B-induced matrixmetalloproteinase expression in human dermal fibroblasts. $J$ Ethnopharmacol 137, 427-33.
5. Fuller B, Smith D, Howerton A, Kern D (2006) Anti-inflammatory effects of CoQ10 and colorless carotenoids. J Cosmet Dermatol 5, 30-8.

6. Jung SK, Lee KW, Kim HY, Oh MH, Byun S, Lim SH, Heo YS, Kang NJ, et al (2010) Myricetin suppresses UVB-induced wrinkle formation and MMP-9 expression by inhibiting Raf. Biochem Pharmacol 79, 1455-61.

7. Quan T, Qin Z, Xia W, Shao Y, Voorhees JJ, Fisher GJ (2009) Matrix-degrading metalloproteinases in photoaging. J Investig Dermatol Symp Proc 14, $20-4$.

8. Brennan M, Bhatti H, Nerusu KC, Bhagavathula N, Kang S, Fisher GJ, Varani J, Voorhees JJ (2003) Matrix metalloproteinase- 1 is the major collagenolytic enzyme responsible for collagen damage in UVirradiated human skin. Photochem Photobiol 78, 43-8.

9. Mukherjee PK, Maity N, Nema NK, Sarkar BK (2011) Bioactive compounds from natural resources against skin aging. Phytomedicine 19, 64-73.

10. Alok S, Jain SK, Verma A, Kumar M, Mahor A, Sabharwal M (2013) Plant profile, phytochemistry and pharmacology of Asparagus racemosus (Shatavari): a review. Asian Pac J Trop Dis 3, 242-51.

11. Potduang B, Meeploy M, Giwanon R, Benmart Y, Kaewduang M, Supatanakul W (2008) Biological activities of Asparagus racemosus. Afr $J$ Tradit Complement Altern Med 5, 230-7.

12. Hayes PY, Jahidin AH, Lehmann R, Penman K, Kitching W, De Voss JJ (2008) Steroidal saponins from the roots of Asparagus racemosus. Phytochemistry 69, 
796-804.

13. Bopana N, Saxena S (2007) Asparagus racemosusEthnopharmacological evaluation and conservation needs. $J$ Ethnopharmacol 110, 1-15.

14. Saxena VK, Chourasia S (2001) A new isoflavone from the roots of Asparagus racemosus. Fitoterapia 72, 307-9.

15. Wiboonpan N, Phuwapraisirisan P, Tip-pyang $S$ (2004) Identification of antioxidant compound from Asparagus racemosus. Phytother Res 18, 771-3.

16. Hossain MI, Sharmin FA, Akhter S, Bhuiyan MA, Shahriar M (2012) Investigation of cytotoxicity and in-vitro antioxidant activity of Asparagus racemosus root extract. Int Curr Pharmaceut J 1, 250-7.

17. Palanisamy N, Manian S (2012) Protective effects of Asparagus racemosus on oxidative damage in isoniazid-induced hepatotoxic rats: an in-vivo study. Toxicol Ind Health 28, 238-44.

18. Kamat JP, Boloor KK, Devasagayam TP, Venkatachalam SR (2000) Antioxidant properties of Asparagus racemosus against damage induced by $\gamma$-radiation in rat liver mitochondria. $J$ Ethnopharmacol 71, 425-35.

19. Therdphapiyanak N, Jaturanpinyo M, Waranuch N, Kongkaneramit L, Sarisuta N (2013) Development and assessment of tyrosinase inhibitory activity of liposomes of Asparagus racemosus extracts. Asian $J$ Pharmaceut Sci 8, 134-42.

20. Mittal S, Dixit PK (2013) In vivo anti-inflammatory and anti-arthritic activity of Asparagus racemosus roots. Int J Pharmaceut Sci Res 4, 2652-8.

21. Velavan S, Begum VMH (2007) Restorative effect of Asparagus racemosus on age related oxidative damage in heart lysosome of aged rats. Int $J$ Pharmacol $3,48-54$.

22. Rungsang $\mathrm{T}$ (2013) Development of nanoemulsion containing Asparagus racemosus extract for cosmetic application. MSc thesis, Naresuan Univ.

23. Gomes SFO, Nunan EA, Ferreira LAM (2004) Influence of the formulation type (o/w, w/o/w emulsions and ointment) on the topical delivery of paromomycin. Rev Bras Ciênc Farm 40, 345-52.

24. Shelmire Jr JB (1956) Factors affecting the diffusion of drugs from vehicles to the skin surface. $J$ Investig Dermatol 27, 383-7.

25. Pitha J, Milecki J, Fales H, Pannell L, Uekama K (1986) Hydroxypropyl- $\beta$-cyclodextrin: preparation and characterization; effects on solubility of drugs. Int $J$ Pharm 29, 73-82.

26. Shakory R, Khodabandeh M, Toliyat T, Azimzadeh S, Sadigh ZA, Badiefar L (2010) Enhancing effect of cyclodextrins on in vitro skin permeation of hGH. Curr Trends Biotechnol Pharm 4, 784-90.

27. Másson M, Loftsson T, Másson G, Stefánsson E (1999) Cyclodextrins as permeation enhancers: Some theoretical evaluations and in vitro testing. J Contr Release 59, 107-18.
28. Onlom C, Khanthawong S, Waranuch N, Ingkaninan K (2014) In vitro anti-Malassezia activity and potential use in anti-dandruff formulation of Asparagus racemosus. Int $J$ Cosmet Sci 36, 74-8.

29. De Paula D, Oliveira DCR, Tedesco AC, Bentley MVLB (2007) Enhancing effect of modified betacyclodextrins on in vitro skin permeation of estradiol. Rev Bras Ciênc Farm 43, 111-20.

30. Scientific Committee on Consumer Safety (2010) SCCS /1358/10: Basic Criteria for the In Vitro Assessment of Dermal Absorption of Cosmetic Ingredients, European Union, pp 1-14.

31. Zillich OV, Schweiggert-Weisz U, Hasenkopf K, Eisner P, Kerscher M (2013) Release and in vitro skin permeation of polyphenols from cosmetic emulsions. Int $J$ Cosmet Sci 35, 491-501.

32. Lampen P, Pittermann W, Heise HM, Schmitt M, Jungmann H, Kietzmann M (2003) Penetration studies of vitamin E acetate applied from cosmetic formulations to the stratum corneum of an in vitro model using quantification by tape stripping, UV spectroscopy, and HPLC. J Cosmet Sci 54, 119-31.

33. Maenthaisong R, Viyoch J, Chaiyakunapruk N, Warnnissorn P (2007) Cleansing lotion containing tamarind fruit pulp extract. II. Study of cumulative irritation effects in human. $J$ Cosmet Dermatol 6, 178-82.

34. Capek I (2004) Degradation of kinetically-stable o/w emulsions. Adv Colloid Interface Sci 107, 125-55.

35. Loftsson T, Brewster ME (1996) Pharmaceutical applications of cyclodextrins. 1. Drug solubilization and stabilization. $J$ Pharmaceut Sci 85, 1017-25.

36. Vaidyanathan R, Chaubal MG, Vasavada RC (1985) Effect of $\mathrm{pH}$ and solubility on in vitro skin penetration of methotrexate from a $50 \% \mathrm{v} / \mathrm{v}$ propylene glycolwater vehicle. Int $J$ Pharm 25, 85-93.

37. Viyoch J, Tengamnuay I, Phetdee K, Tuntijarukorn P, Waranuch N (2010) Effects of trans-4-(aminomethyl) cyclohexanecarboxylic acid/potassium azeloyl diglycinate/niacinamide topical emulsion in Thai adults with melasma: a single-center, randomized, double-blind, controlled study. Curr Ther Res 71, 345-59. 